\title{
New cancer cases attributable to diet among adults aged 30-84 years in France in 2015
}

\author{
Kevin D. Shield ${ }^{1 *}$, Heinz Freisling ${ }^{2}$, Marie-Christine Boutron-Ruault ${ }^{3}$, Mathilde Touvier ${ }^{4}$, \\ Claire Marant Micallef ${ }^{1}$, Mazda Jenab ${ }^{2}$, Valérie Deschamps ${ }^{5,6}$, Catherine Hill ${ }^{7}$, Pietro Ferrari ${ }^{2}$, \\ Irène Margaritis $^{8}$, Freddie Bray ${ }^{1}$ and Isabelle Soerjomataram ${ }^{1}$ \\ ${ }^{1}$ Section of Cancer Surveillance, International Agency for Research on Cancer, 69372 Lyon, France \\ ${ }^{2}$ Section of Nutrition and Metabolism, International Agency for Research on Cancer, 69372 Lyon, France \\ ${ }^{3}$ U1018, Lifestyle, Genes and Health: Integrative Trans-Generational Epidemiology, Centre for Research in Epidemiology and \\ Population Health (CESP), INSERM, 94805 Villejuif, France \\ ${ }^{4}$ UMR 1153, Centre de Recherche en Epidémiologie et Statistiques Sorbonne Paris Cité, INSERM, 75004 Paris, France \\ ${ }^{5}$ Nutritional Surveillance and Epidemiology Team (ESEN), French Public Health Agency, Paris-13 University, 93017 Paris, \\ France \\ ${ }^{6}$ Centre de recherche en épidémiologie et statistiques, COMUE Sorbonne Paris Cité, 93017 Bobigny, France \\ ${ }^{7}$ Biostatistics and Epidemiology Department, Institut Gustave Roussy, 94800 Villejuif, France \\ ${ }^{8}$ Nutrition Risk Assessment Unit, French Agency for Food, Environmental and Occupational Health and Safety (ANSES), 94701 \\ Maisons-Alfort Cedex, France
}

(Submitted 25 September 2017 - Final revision received 16 July 2018 - Accepted 1 August 2018)

\begin{abstract}
This study aimed to estimate the number of new cancer cases attributable to diet among adults aged 30-84 years in France in 2015, where convincing or probable evidence of a causal association exists, and, in a secondary analysis, where at least limited but suggestive evidence of a causal association exists. Cancer cases attributable to diet were estimated assuming a 10-year latency period. Dietary intake data were obtained from the 2006 French National Nutrition and Health Survey. Counterfactual scenarios of dietary intake were based on dietary guidelines. Corresponding risk relation estimates were obtained from meta-analyses, cohort studies and one case-control study. Cancer incidence data were obtained from the French Network of Cancer Registries. Nationally, unfavourable dietary habits led to 16930 new cancer cases, representing $5.4 \%$ of all new cancer cases. Low intake of fruit and dietary fibre was the largest contributor to this burden, being responsible for 4787 and 4389 new cancer cases, respectively. If this is expanded to dietary component and cancer pairs with at least limited but suggestive evidence of a causal association, 36049 new cancer cases, representing $11.6 \%$ of all new cancer cases, were estimated to be attributable to diet. These findings suggest that unfavourable dietary habits lead to a substantial number of new cancer cases in France; however, there is a large degree of uncertainty as to the number of cancers attributable to diet, including through indirect mechanisms such as obesity, and therefore additional research is needed to determine how diet affects cancer risk.
\end{abstract}

Key words: Diet: Cancer: Cancer cases attributable to diet: France: Burden of disease

The quality of a diet can have a large impact on the health of an individual $^{(1-3)}$ and a population ${ }^{(2-4)}$. In particular, dietary intake of micronutrients, antioxidants, fibre and phytochemicals decreases the risk of developing cancer ${ }^{(5,6)}$, whereas the intake of polycyclic aromatic hydrocarbons and heterocyclic aromatic amines $^{(7)}$ may increase the risk of cancer. Furthermore, differences in dietary intake across populations may explain large differences in cancer burden globally ${ }^{(4,8)}$. Thus, up-to-date information on the number of new cancer cases attributable to unfavourable dietary habits at the national level is needed to formulate and implement sustainable, comprehensive and effective national public health programmes that are aimed at improving dietary intake and population health ${ }^{(2,3,9,10)}$.

Previous estimates of the impact of diet on cancer risk at the population level are wide-ranging, as there has been conflicting evidence of this impact ${ }^{(11-14)}$. However, recently, there has been increasingly more accurate evidence of the association between dietary intake and the risk of developing cancer,

Abbreviations: CUP, Continuous Update Project: ENNS, National Nutrition and Health Survey (Étude Nationale Nutrition Santé): IARC, International Agency for Research on Cancer: PAF, population-attributable fractions: RR, relative risk: WCRF, World Cancer Research Fund.

* Corresponding author: K. D. Shield, email kevin.david.shield@gmail.com 
owing to the publication of results from prospective cohort studies with increased durations of follow-up, and the increasing use of dietary biomarkers ${ }^{(15)}$. Therefore, the first aim of this study was to estimate the number of new cancer cases in France in 2015 that would not have occurred if everyone in France met the dietary recommendations for the consumption of fruit, vegetables, fibre and dairy products, and did not exceed the dietary recommendations for the consumption of red and processed meats. Second, this study aimed to estimate the number of new cancer cases attributable to diet where a causal relationship between dietary intake and the development of cancer has not yet been established, but where there is at least limited but suggestive evidence of a causal relationship.

\section{Methods}

The number of attributable cases - that is, the number of cancer cases that would have been avoided if everyone's diet matched population-level recommendations - was estimated based on an attributable-fraction methodology assuming a 10-year average latency period between dietary intake and the diagnosis of cancer $^{(16)}$. Dietary components and the corresponding causally related cancer sites included in the study were based on there being at least probable evidence of a causal relationship (i.e. limited evidence of causality in humans) according to the International Agency for Research on Cancer (IARC) monographs ${ }^{(17)}$. If the dietary factor was not evaluated by the IARC monograph programme, the dietary component and the corresponding causally related cancer sites were based on there being at least probable evidence of causality according to the World Cancer Research Fund's (WCRF)/American Institute for Cancer Research's Continuous Update Project (CUP) ${ }^{(5,18-29)}$. Last, for exposures related to breast cancer, dietary components were evaluated based on there being probable evidence of causality according to the French National Cancer Institute (Institut National Du Cancer or INCa) ${ }^{(30)}$ (online Supplementary Tables S1 and S2). For evidence of causality, a data closure date of June 2017 was used.

The present analysis examined the cancer cases attributable to dietary intake for those individuals aged $30-84$ years. Cancers diagnosed in individuals aged 29 years and younger were not examined owing to the complex aetiology of cancers that occur earlier in life. Furthermore, we excluded cancers that occurred in people aged 85 years and older in 2015 , as dietary intake data were not available for individuals who were 75 years of age and older in 2005.

\section{Dietary intake data}

Dietary intake data were obtained from the 2006 National Nutrition and Health Survey (Étude Nationale Nutrition Santé or ENNS) ${ }^{(31)}$, which was chosen over the Etude individuelle nationale sur les consummations alimentaires 2 (Individual and National Study on Food Consumption 2) ${ }^{(32)}$ owing to the former's larger sample size. The 2006 ENNS is a general population-stratified, three-stage telephone (first contact on both home phones and cellphones) and in-person survey of adults aged 18-74 years that was conducted between February 2006 and March 2007. Only survey data from individuals aged 20-74 years were used in this study. In each household contacted, the person who had the nearest birthday to the interview date, who lived in the house for at least $5 \mathrm{~d}$ of the week and who was eligible for inclusion in the survey (see Unité de surveillance et d'épidémiologie nutritionnelle ${ }^{(31)}$ for inclusion criteria) was chosen to participate.

Dietary intake was assessed by two randomly distributed 24-h recalls within a period of 2 weeks, one of which was assigned on a weekend, with individuals not being previously informed of the call days. Trained dietitians asked subjects to describe the foods and beverages consumed the day before the interview, from midnight to midnight. Subjects were asked for information on composition, recipes and brands of the foods and beverages consumed, which were described with the aid of a validated photography manual ${ }^{(33)}$ or as per standard measurements (grams, etc.). Nutritional values were obtained from a published nutrient database ${ }^{(34)}$. Information on added salt during food preparation was collected separately. Dietary intake data were provided to the authors in categories (online Supplementary Fig. S2-S8).

Of the individuals who participated in the dietary survey ( $n$ 3115; response rate 60.5\%), 361 individuals were excluded for under-reporting (as identified by the method outlined by Black $^{(35)}$ ). The 2006 ENNS weighted individuals by stratum, sex, age, education and whether the surveyed household included at least one child. The overall response rate, based on the hypothesised number of eligible individuals and individuals who accurately reported their dietary intake ( $n$ 2734), was $53 \cdot 1 \%$.

\section{Dietary guidelines}

As this study was applied to population-level data on cancer incidence, population guidelines were chosen over individual guidelines (see Institut national de prévention et d'éducation pour la santé(2) and Ministère du Travail de l'Emploi et de la Santé(3) for French-specific individual guidelines). Population guidelines for dietary intake were obtained from the $\mathrm{WCRF}^{(36-38)}$. Specifically, the WCRF recommends at the population level the dietary intake of at least $600 \mathrm{~g} / \mathrm{d}$ of fruit and vegetables $^{(36)}$, at least $25 \mathrm{~g} / \mathrm{d}$ of fibre ${ }^{(36)}$ (NSP), no more than $300 \mathrm{~g} /$ week of red meat $(42.9 \mathrm{~g} / \mathrm{d})^{(37)}$ and very little, if any, processed red meat (i.e. $0 \mathrm{~g} / \mathrm{d})^{(37)}$. The recommended intake of fruit and vegetables separately was based on a $50 \%$ intake of fruit and a $50 \%$ intake of vegetables. This was similar to the mean intake of fruit $(185.6 \mathrm{~g} / \mathrm{d})$ and mean intake of vegetables $(195.5 \mathrm{~g} / \mathrm{d})$ divided by the mean intake of fruit and vegetables $(381 \cdot 1 \mathrm{~g} / \mathrm{d})$ as measured by the 2006 ENNS (Table 1), and similar to the methods used by Parkin ${ }^{(39)}$.

Dietary intake guidelines for dairy products of 2 servings/d (where a serving is $150 \mathrm{ml}$ of milk, $30 \mathrm{~g}$ of cheese, $125 \mathrm{~g}$ of yogurt, $100 \mathrm{~g}$ of fromage blanc and $120 \mathrm{~g}$ of petits suisses) were based on individual guidelines from the French High Council for Public Health (Haut Conseil de la santé publique) ${ }^{(40)}$ as no such WCRF population guidelines exist for the intake of dairy products.

\section{Population-attributable fractions for individual dietary risk factors}

The population-attributable fractions (PAF) of new cancer cases attributable to diet were estimated by age, sex, cancer subtype and dietary component ${ }^{(4,41)}$ according to Eq. (1), where the 
Table 1. Main analysis to estimate the number of new cancer cases in France in 2015 attributable to diet (Relative risks (RR) and $95 \%$ confidence intervals)

\begin{tabular}{|c|c|c|c|c|c|}
\hline Risk factor & Cancer site & $\mathrm{RR}^{*}$ & $95 \% \mathrm{Cl}$ & $\begin{array}{l}\text { Dietary change (from } \\
\text { recommended intake) }\end{array}$ & Source \\
\hline \multicolumn{6}{|l|}{ Fruit (low) } \\
\hline & $\begin{array}{l}\text { Oral cavity, pharynx and larynx (excluding } \\
\text { nasopharynx) (C01-10, C12-13 and C32) }\end{array}$ & 1.05 & $0.99,1.12$ & $100 \mathrm{~g} / \mathrm{d}$ decrease & $\begin{array}{l}\text { Combination of Bradbury et al. }{ }^{(85)} \\
\text { and Freedman et al. }{ }^{(84)}\end{array}$ \\
\hline & Bronchus and lung (C33-34) & 1.09 & $1.05,1 \cdot 12$ & $100 \mathrm{~g} / \mathrm{d}$ decrease & Vieira et al. ${ }^{(87)}$ \\
\hline \multicolumn{6}{|c|}{ Vegetables (low)† } \\
\hline & $\begin{array}{l}\text { Oral cavity, pharynx and larynx (excluding } \\
\text { nasopharynx) (C01-10, C12-13 and C32) }\end{array}$ & $1 \cdot 14$ & $0.98,1.33$ & $100 \mathrm{~g} / \mathrm{d}$ decrease & $\begin{array}{l}\text { Combination of Bradbury et al. }{ }^{(85)} \\
\text { and Freedman et al. }{ }^{(84)}\end{array}$ \\
\hline \multicolumn{6}{|c|}{ Dietary fibre (low) } \\
\hline & Colorectum (C18-20) & 1.11 & $1.06,1 \cdot 16$ & $10 \mathrm{~g} / \mathrm{d}$ decrease & Aune et al. ${ }^{(88)}$ \\
\hline & Breast (C50) & 1.05 & $1.02,1.10$ & $10 \mathrm{~g} / \mathrm{d}$ decrease & Aune et al. ${ }^{(89)}$ \\
\hline \multicolumn{6}{|c|}{ Dairy products (low) } \\
\hline & Colorectum (C18-20) & $1.08 \ddagger$ & $1 \cdot 05,1 \cdot 13$ & $\begin{array}{l}\text { One serving/d } \\
\text { decrease }\end{array}$ & Aune et al. ${ }^{(83)}$ \\
\hline \multicolumn{6}{|c|}{ Red meat (high)§ } \\
\hline & Colorectum (C18-20) & 1.17 & $1.05,1.31$ & $100 \mathrm{~g} / \mathrm{d}$ increase & Chan et al. ${ }^{(90)}$ \\
\hline & Pancreas (C25) & $1 \cdot 11$ & $0.94,1.32$ & $100 \mathrm{~g} / \mathrm{d}$ increase & Larsson and Wolk ${ }^{(91)}$ \\
\hline \multicolumn{6}{|c|}{ Processed meat (any) } \\
\hline & Stomach (non-cardia) (C16.0) & $1 \cdot 18$ & $1.01,1.38$ & $100 \mathrm{~g} / \mathrm{d}$ increase & $\operatorname{WCRF}^{(19)}$ \\
\hline & Colorectum (C18-20) & 1.39 & $1.21,1.64$ & $100 \mathrm{~g} / \mathrm{d}$ increase & Chan et al. ${ }^{(90)}$ \\
\hline
\end{tabular}

WCRF, World Cancer Research Fund.

* RR were standardised based on common unit decreases for low dietary intake and common unit increases for high dietary intake.

† Limited to non-starchy vegetables when possible.

$\ddagger$ Based on the RR for milk (standardised to serving size)

$\S$ The RR for prostate cancer was $1.00(95 \% \mathrm{Cl} 0.95,1.05)$ and therefore was not included in the analysis ${ }^{(92)}$.

observed prevalence of an observed dietary intake $P$ for an exposure category $x$ is combined with data on the relative risk (RR) of cancer (where the reference category is the dietary guideline). The mean exposure was modelled based on the midpoint of categorical exposures. Furthermore, the mean exposure of the top exposure category was estimated by adding half the range of the preceding exposure category to the lower boundary of the top exposure category. The RR were obtained from meta-analyses, cohort studies and in one case from a hospital-based case-control study (Table 1 and online Supplementary Tables S4 and S5).

$$
\mathrm{PAF}=\frac{\sum_{x=1}^{n} P_{x}\left(\mathrm{RR}_{x}-1\right)}{\sum_{x=1}^{n} P_{x} \mathrm{RR}_{x}}
$$

\section{Population-attributable fractions for all dietary risk factors}

In cases in which the risk of a specific cancer subtype is affected by one dietary component, the PAF for all dietary factors $\left(\mathrm{PAF}_{\mathrm{T}}\right)$ is equal to the dietary component PAF. In cases in which several dietary factors, indexed by $i=1,2, \ldots d$, modify the risk of the same cancer subtype, the $\mathrm{PAF}_{\mathrm{T}}$ were estimated by age, sex and cancer subtype using Eq. (2). This method assumes that dietary intakes are independent and that the RR are multiplicative.

$$
\mathrm{PAF}_{\mathrm{T}}=1-\prod_{i=1}^{d}\left(1-\mathrm{PAF}_{i}\right)
$$

\section{Cancer incidence and population data}

The number of new cancer cases in France in 2015 was projected based on 2013 incident rates obtained from the French Cancer Registries Network (FRANCIM) ${ }^{(42)}$. These projections were performed by applying cancer incidence rates observed in 2013-2015 national population data ${ }^{(43)}$.
This method assumes the age-specific incidence rates to be the same in 2013 and 2015. Population data for France were obtained from the National Institute of Statistics and Economic Studies (Institut national de la statistique et des études économiques) ${ }^{(43)}$.

\section{Attributable numbers}

Attributable numbers were obtained by multiplying age, sex and cancer subtype-specific PAF by corresponding cancer incidence numbers.

\section{Secondary analysis}

The secondary analysis estimated the number of cancer cases attributable to diet and the associated cancer sites where there was at least limited evidence of a causal relationship according to the IARC monographs (for red and processed meats) ${ }^{(17)}$, limited-suggestive evidence according to the WCRF CUP ${ }^{(5,18-29)}$ and suggestive evidence according to $\mathrm{INCa}^{(30)}$. Dietary salt intake was included in the secondary analysis (Table 2). Population-level dietary recommendations were obtained from the WCRF for salt $\left(<5 \mathrm{~g} / \mathrm{d}\right.$ from all sources $\left.{ }^{(38)}\right)$.

\section{Uncertainty estimations}

Uncertainty estimates (i.e. standard error) were available for the exposure (dietary intake) and RR data. However, uncertainty estimates for the cancer incidence data were not available. Thus, we were able to estimate the 95\% uncertainty intervals (UI) for the age, sex and cancer-specific PAF (for the methodology used, see the online Supplementary Material, and for the $95 \%$ UI estimates, see the online Supplementary Excel File). 
Table 2. Dietary intake in France in 2006 of fruit, vegetables, dietary fibre, dairy products, red and processed meats and salt among adults aged $20-74$ years

\begin{tabular}{|c|c|c|c|c|c|c|c|}
\hline \multirow[b]{2}{*}{ Food group and analysis } & \multirow[b]{2}{*}{$\begin{array}{l}\text { Recommended } \\
\text { intake }\end{array}$} & \multicolumn{2}{|r|}{ Men } & \multicolumn{2}{|r|}{ Women } & \multicolumn{2}{|r|}{ Total } \\
\hline & & $\begin{array}{l}\text { Mean } \\
\text { intake }\end{array}$ & $\begin{array}{l}\text { Proportion adequate } \\
\text { intake }(\%)\end{array}$ & $\begin{array}{l}\text { Mean } \\
\text { intake }\end{array}$ & $\begin{array}{l}\text { Proportion adequate } \\
\text { intake }(\%)\end{array}$ & $\begin{array}{l}\text { Mean } \\
\text { intake }\end{array}$ & $\begin{array}{l}\text { Proportion adequate } \\
\text { intake }(\%)\end{array}$ \\
\hline \multicolumn{8}{|l|}{ Main analysis } \\
\hline Fruit* & $\geq 300 \mathrm{~g} / \mathrm{d}$ & $172 \cdot 6$ & 29 & $181 \cdot 7$ & 30 & $177 \cdot 2$ & 30 \\
\hline Vegetables (non-starchy) ${ }^{*}$ & $\geq 300 \mathrm{~g} / \mathrm{d}$ & $189 \cdot 0$ & 31 & $192 \cdot 7$ & 29 & $190 \cdot 9$ & 30 \\
\hline Dietary fibre & $\geq 25 \mathrm{~g} / \mathrm{d}$ & 18.9 & 20 & $16 \cdot 1$ & 10 & $17 \cdot 4$ & 15 \\
\hline Dairy products $†$ & 2 servings/d & $2 \cdot 9$ & 65 & $2 \cdot 4$ & 56 & $2 \cdot 6$ & 61 \\
\hline Red meat & $\leq 42.9 \mathrm{~g} / \mathrm{d}$ & 81.9 & 30 & $55 \cdot 9$ & 45 & 68.6 & 38 \\
\hline Processed meat & $0 \mathrm{~g} / \mathrm{d}$ & 43.9 & 13 & 29.5 & 16 & $36 \cdot 5$ & 15 \\
\hline \multicolumn{8}{|l|}{ Secondary analysis only } \\
\hline Salt & $<5 \mathrm{~g} / \mathrm{d}$ & $8 \cdot 7$ & 16 & $6 \cdot 2$ & 51 & 7.4 & 34 \\
\hline
\end{tabular}

* Based on a dietary recommendation of $600 \mathrm{~g} / \mathrm{d}$ of fruit and vegetables combined (excluding fruit juices with added sugar and dried vegetables).

† Where a serving is equal to $150 \mathrm{ml}$ of milk, $30 \mathrm{~g}$ of cheese, $125 \mathrm{~g}$ of yogurt, $100 \mathrm{~g}$ of fromage blanc and $120 \mathrm{~g}$ of petits suisses.

$\ddagger$ Based on a guideline of $300 \mathrm{~g}$ of red meat per week.

\section{Results}

In France in 2006 (Table 2), 70, 70, 85 and 39\% of adults aged 20-74 years had low dietary intake of fruit, vegetables, fibre and dairy products, respectively. Furthermore, $62 \%$ of these adults had high consumption of red meat and $85 \%$ of these adults consumed processed meat. The proportions of men and women with low intake of fruit and vegetables were similar, and the proportions of men and women who consumed processed meat were similar. However, women were more likely to have low dietary fibre and dairy product intake, whereas men were more likely to have high red meat intake.

In France in 2015, of the 310687 newly diagnosed cancer cases among adults aged 30-84 years, 16930 were attributable to diet, representing $5.4 \%$ of all new cancer cases (Table 3), when based on dietary components and causally related cancer sites with at least probable evidence. The overall number of new cancer cases was slightly higher among men compared with women, with 10058 and 6872 new cancer cases being diagnosed in men and women, respectively, representing 5.8 and $5.0 \%$ of all new cancer cases among men and women, respectively. The leading contributors to new cancer cases attributable to diet were low intake of fruit and dietary fibre, with 4787 and 4389 new cancer cases attributable to these risk factors, respectively. However, the impact of dietary risk factors on the number of cancer cases differed by sex; for women, the leading contributors to new cancer cases attributable to diet were low intake of dietary fibre and intake of processed meat, whereas for men the leading contributors were low intake of fruit and intake of processed meat. Furthermore, colorectal (7557 cases) and lung (3924 cases) cancers were the most frequently diagnosed cancers attributable to diet (Fig. 1).

If the dietary components and causally related cancer sites were expanded to include those with at least limited but suggestive evidence of an association, it was estimated that 36049 new cancer cases, representing $11.6 \%$ of all new cancer cases, were attributable to diet (Fig. 2 and online Supplementary Table S6). The number of these estimated cancer cases attributable to diet was higher among men compared with women, with 23939 and 12110 new cancer cases, respectively, representing 13.7 and $8.9 \%$ of all new cancer cases among men and women, respectively. Furthermore, the secondary analysis indicated that intake of processed meat (9258 cases) and low intake of fruit (7936 cases) were the most important dietary components contributing to these new cancer cases.

\section{Discussion}

This study estimated that in France, as in other countries ${ }^{(44-46)}$, diet is an important cause of cancer; in France in 2015, 5.4\% of all incident cases among adults aged 30-84 years - over 16000 new cancer cases - were attributable to diet, with low intake of fruit and dietary fibre being the largest contributors. Furthermore, when expanded to dietary components and cancer sites where at least limited but suggestive evidence of an association exists, an estimated $11.6 \%$ of all incident cases - over 36000 new cancer cases - were attributable to diet.

The importance of dietary factors differed between men and women in France. Low dietary fibre intake, which was more prevalent among women and which is causally related to breast cancer $^{(30)}$, was responsible for a larger number of new cancer cases among women compared with men. Conversely, low intake of fruit and vegetables led to a larger number of new cancer cases among men compared with women, partly owing to a slightly higher prevalence of low intake of fruit among men, and an increased risk of oral cavity, pharyngeal and lung cancers among men ${ }^{(31)}$.

Other dietary components that have probable evidence of decreasing the risk of cancer (including garlic and foods containing carotenoids), as well as dietary components that increase the risk of cancer (including mate, foods preserved by salting and $\beta$-carotene supplements), all of which, as assessed by the WCRF CUP ${ }^{(5,18-20)}$, were not included in the analysis owing to either rare consumption in France and/or a lack of information on their consumption in France. Furthermore, the risk relationship between $\mathrm{Ca}$ and the development of cancer was excluded owing to a lack of data and an overlap with dairy product consumption. In addition, carcinogenic food contaminants, such as aflatoxin, were not included in this study as 
Table 3. Number of new cancer cases in 2015 attributable to diet among French adults aged 30-84 years, as well as population-attributable fractions (PAF), by dietary component and cancer site, for cancer and exposure pairs with probable (International Agency for Research on Cancer (IARC)), probable (World Cancer Research Fund (WCRF)) or convincing (Institut National Du Cancer (INCa)) evidence*

\begin{tabular}{|c|c|c|c|c|c|c|}
\hline \multirow[b]{2}{*}{ Risk factor and cancer site (ICD-10 codes) } & \multicolumn{2}{|l|}{ Men } & \multicolumn{2}{|l|}{ Women } & \multicolumn{2}{|l|}{ Total } \\
\hline & Attributable cases & PAF $(\%) \dagger$ & Attributable cases & PAF $(\%) \dagger$ & Attributable cases & PAF $(\%) \dagger$ \\
\hline \multicolumn{7}{|l|}{ Fruit } \\
\hline Oral cavity, pharynx and larynx (C01-13 and C32) & 706 & $6 \cdot 3$ & 157 & $5 \cdot 7$ & 863 & $6 \cdot 2$ \\
\hline Lung (C33-34) & 2870 & $10 \cdot 5$ & 1054 & $10 \cdot 1$ & 3924 & $10 \cdot 4$ \\
\hline Total (C00-97) & 3576 & $2 \cdot 1$ & 1211 & 0.9 & 4787 & 1.5 \\
\hline \multicolumn{7}{|l|}{ Vegetables } \\
\hline Oral cavity, pharynx and larynx (C01-13 and C32) & 1477 & $13 \cdot 2$ & 359 & $13 \cdot 1$ & 1836 & $13 \cdot 2$ \\
\hline Total (C00-97) & 1477 & 0.8 & 359 & 0.3 & 1836 & 0.6 \\
\hline \multicolumn{7}{|l|}{ Dietary fibre } \\
\hline Colorectum (C18-20) & 1090 & 5.7 & 1131 & $8 \cdot 2$ & 2221 & $6 \cdot 7$ \\
\hline Breast (C50) & - & - & 2168 & 4.4 & 2168 & 4.4 \\
\hline Total (C00-97) & 1090 & 0.6 & 3299 & $2 \cdot 4$ & 4389 & 1.4 \\
\hline \multicolumn{7}{|l|}{ Dairy products } \\
\hline Colorectum (C18-20) & 410 & $2 \cdot 1$ & 374 & $2 \cdot 7$ & 785 & $2 \cdot 4$ \\
\hline Total (C00-97) & 410 & 0.2 & 374 & 0.3 & 785 & 0.3 \\
\hline \multicolumn{7}{|l|}{ Red meatł } \\
\hline Colorectum (C18-20) & 1106 & $5 \cdot 8$ & 463 & $3 \cdot 3$ & 1569 & $4 \cdot 8$ \\
\hline Pancreas (C25) & 193 & 3.7 & 94 & $2 \cdot 1$ & 286 & 3.0 \\
\hline Total (C00-97) & 1298 & 0.7 & 557 & 0.4 & 1856 & 0.6 \\
\hline \multicolumn{7}{|l|}{ Processed meat } \\
\hline Stomach (non-cardia) (C16.0) & 297 & $12 \cdot 7$ & 120 & $8 \cdot 8$ & 417 & $11 \cdot 3$ \\
\hline Colorectum (C18-20) & 2439 & $12 \cdot 7$ & 1223 & 8.8 & 3663 & $11 \cdot 1$ \\
\hline Total (C00-97) & 2737 & 1.6 & 1343 & 1.0 & 4080 & 1.3 \\
\hline \multicolumn{7}{|l|}{ Total } \\
\hline Total (C00-97) & 10058 & $5 \cdot 8$ & 6872 & $5 \cdot 0$ & 16930 & 5.4 \\
\hline
\end{tabular}

* Evidence was taken first from IARC (red and processed meat intake), then WCRF and then INCa. Evidence of causality from INCa was used for exposures related to breast cancer risk. Total PAF estimates were corrected for overlap between dietary risk factors (Eq. (2)).

† PAF were computed using Eq. (1) for individual risk factors and Eq. (2) for all dietary factors.

$\ddagger$ The relative risk for prostate cancer was $1.00(95 \% \mathrm{Cl} 0.95,1.05)$ and therefore was not included in the analysis ${ }^{(92)}$.
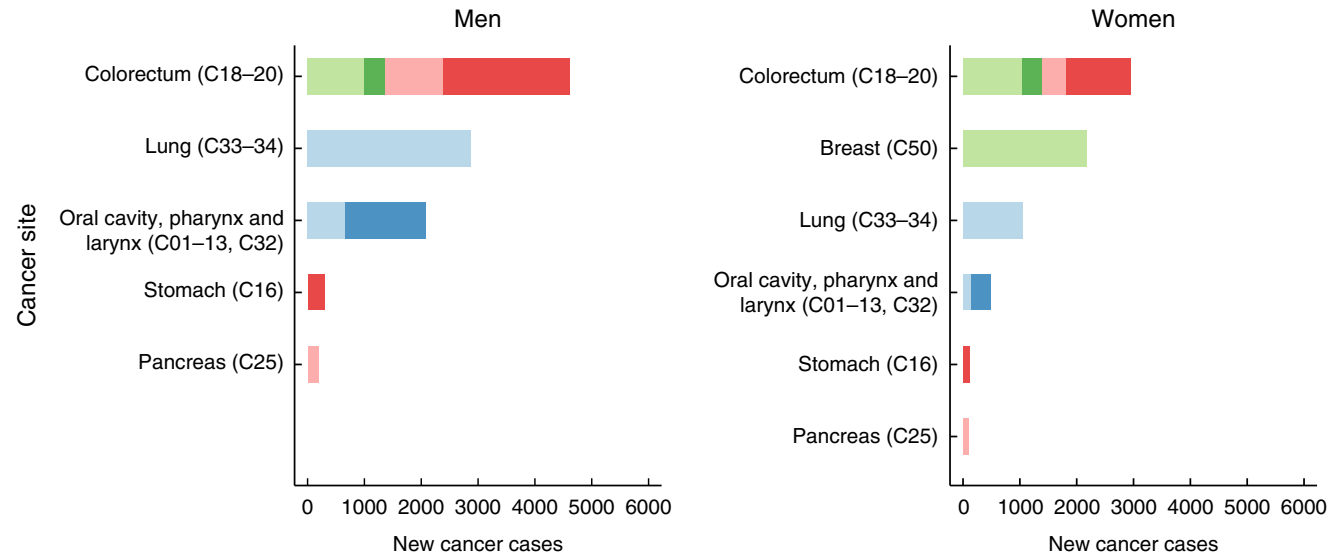

Fig. 1. Number of new cancer cases in 2015 attributable to dietary risk factors among French men and women aged $30-84$ years for dietary intake and cancer pairs

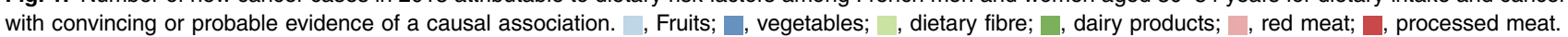

these contaminants were not classified as a form of nutrition and owing to limited data availability ${ }^{(47)}$. This study also did not include food preparation or the manner in which food is served as a risk factor, such as the consumption of hot beverages ${ }^{(48)}$, owing to a lack of information in this regard and the fact that this risk is not directly related to nutritional intake. The method of assessing whether the intake of a dietary component is causally related to cancer sometimes differs between IARC, WCRF and INCa. Therefore, the sensitivity analysis included components that these three organisations had assessed as having at least limited but suggestive evidence of a causal association with cancer. Coffee was excluded from the analysis owing to the findings of the IARC monographs, which differed from WCRF CUP findings; thesedifferences may be because of an inadequate control for smoking and exposure to other carcincogens among heavy coffee consumers ${ }^{(21,25,48)}$.

Despite the uncertainty in the number of cancers attributable to diet, the results of the present analysis indicate that the effect of diet on cancer should be considered by policy-makers when formulating and implementing sustainable, comprehensive and 

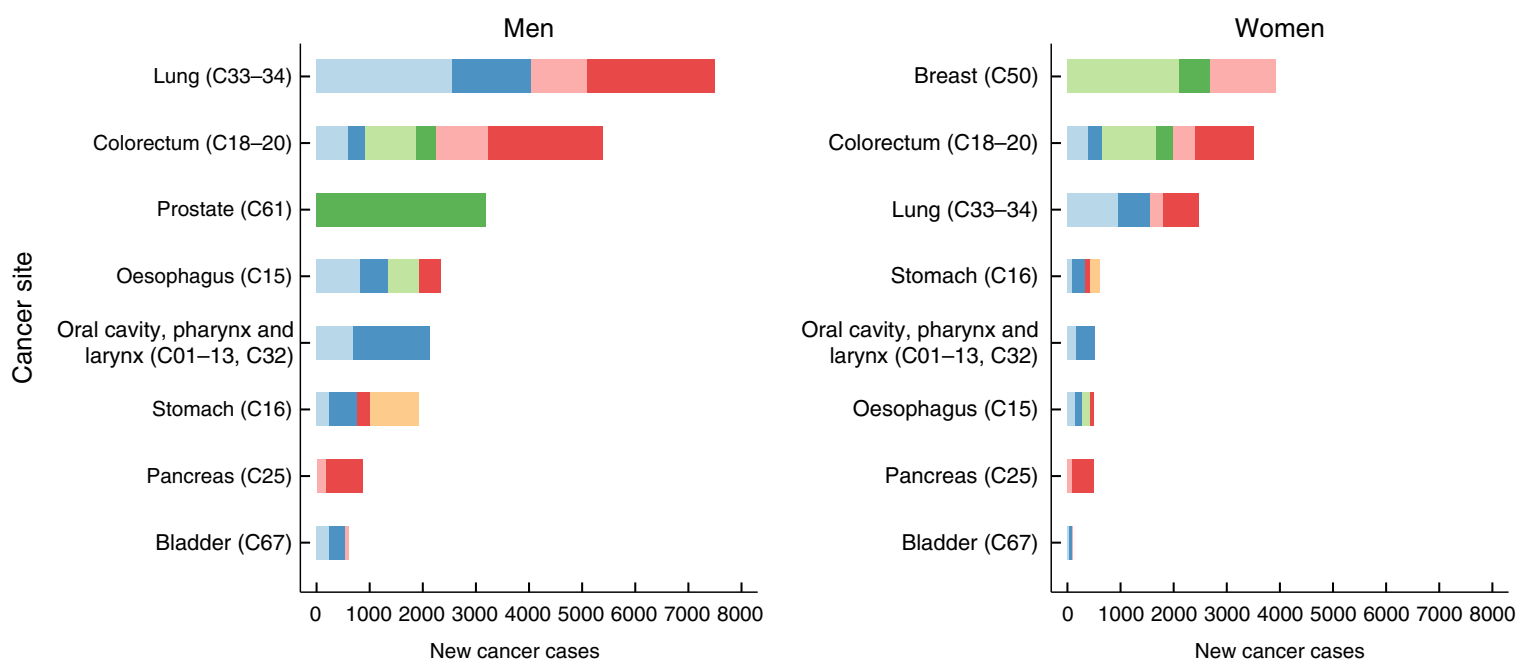

Fig. 2. Number of new cancer cases in 2015 attributable to dietary risk factors among French men and women aged 30-84 years for dietary intake and cancer pairs with at least limited but suggestive evidence of a causal association (secondary analysis). $\ldots$, Fruits; $\square$, vegetables; $\square$, dietary fibre; $\square$, dairy products; $\square$, red meat; $\square$, processed meat; , salt.

effective national public health programmes that are aimed at improving dietary intake and population health ${ }^{(2,3,9,10)}$. Furthermore, dietary intake as a risk factor is highly correlated with other risk factors for cancer ${ }^{(49)}$, such as obesity, insufficient physical activity and sedentary behaviours ${ }^{(50,51)}$. As such, the efforts of the French Agency for Food, Environmental and Occupational Health and Safety (Agence nationale de sécurité sanitaire de l'alimentation, de l'environnement et du travail) to promote healthy dietary practices are coordinated with the promotion of physical activity ${ }^{(52)}$. Furthermore, the WHO has developed a global strategy to address both diet and physical $\operatorname{activity}^{(53)}$.

The results of this study are based on cross-sectional data and do not take into account trends in dietary intake, which are important in France and in other countries ${ }^{(54)}$. Specifically, the intake of vegetables and fruit increased and the consumption of red meat, cereals, other fibre-containing foods and dairy products decreased in France from 1999 to $2007^{(32)}$. Furthermore, in France, from 1999 to 2007, younger individuals consumed fewer fruit and vegetables and consumed more meat (men only) when compared with older individuals ${ }^{(32)}$. The current impact of these dietary patterns on the cancer profile in France is moderated by the relatively small number of new cancer cases among young men (as compared with older men); however, if sustained later in life, such dietary patterns will lead to a higher number of cancers in the future that will be attributable to diet.

The dietary intake needs of individuals are heterogenous, and therefore one dietary intake value may not fit everyone in a population, but dietary recommendations are typically designed to cover the nutritional requirements of more than $98 \%$ of individuals in a given population ${ }^{(55)}$. To model the counterfactual scenario of optimal population diet, the current study used population guidelines (except in the case of dairy product intake where individual guidelines were used). These guidelines represent the population average intake that is judged to be consistent with optimal health in a population ${ }^{(56)}$; population guidelines are typically higher than individual or personal guidelines, and they ensure that individual requirements are met ${ }^{(55)}$. However, both types of guidelines are based on overall health, and not on a reduction in cancer risk in particular $^{(10,57-62)}$. With respect to the association between diet and the risk of cancer, there is little evidence available regarding the theoretical minimum risks; however, a plateau effect exists whereby additional consumption of dietary items, such as fruit and vegetables, does not lead to a further decrease in cancer risk ${ }^{(1)}$. In addition, the feasibility of dietary guidelines being adopted by the public is also considered, and therefore, owing to the subjective nature of setting guidelines, the daily intake recommended for various food categories often varies between recommending organisations ${ }^{(10,58-62)}$, which may lead to differences in the number of cancers estimated as being attributable to diet ${ }^{(44-46)}$.

The results of this analysis should also be interpreted in light of the limitations of the analysis. Dietary recommendations for fruit and vegetable intake are often provided as a combined amount. Thus, for this study, a recommended split of $50 \%$ fruit and $50 \%$ vegetables was used, similar to the relative consumption of fruit to vegetables in France (and in a similar manner to the method used by Parkin ${ }^{(39)}$ ). However, other dietary guidelines, such as those for Australia and the USA, recommend a higher daily intake of vegetables compared with fruit $^{(60,62)}$.

Foods and nutrients are not ingested alone, and thus dietary intake patterns may have a combined effect on cancer risk ${ }^{(63,64)}$. In particular, the consumption of vegetables, fruit and grains (a major source of fibre) are strongly correlated, whereas the consumption of red meat, processed meat and high-fat dairy products are strongly correlated ${ }^{(65-67)}$. Furthermore, the impact of particular risk factors has been determined usually by examining the impact of 'isolated nutrients' on cancer risk, rather than by examining the impact of 'dietary patterns' on cancer risk ${ }^{(68)}$, which would account for possible interactions between dietary components ${ }^{(69)}$. However, with the accumulation of epidemiological evidence, there is a need for future robust meta-analyses of dietary patterns (consistently defined) 
and the associated cancer risks, to enable studies that assess the impact of dietary patterns on country-level cancer profiles. For example, the effects of dietary intake of fruit and vegetables on cancer incidence rates and the effects of dietary intake of fibre on cancer incidence rates are likely to overlap, as fruit and vegetables sources of fibre in one's diet ${ }^{(70)}$. However, as with other studies that estimated the PAF owing to dietary intake $^{(44-46)}$, the PAF for total dietary intake in France was estimated assuming independence between various dietary components. This assumption of independence between factors was made owing to the unavailability of dietary intake cross-tabulation data. Thus, as with other studies of the effects of dietary intake on the number of new cancer cases ${ }^{(44)}$, the total number of new cancers attributable to all dietary risk factors may be overestimated owing to these nutritional intake correlations. Furthermore, dietary intakes are also correlated with other cancer risk factors, such as a family history of cancer, smoking, insufficient physical activity, the consumption of alcohol, use of hormonal treatment for menopause (among women), number of children (among women) and use of oral contraceptives (among women) ${ }^{(67,71)}$. These dietary intake and risk correlations may lead to an overestimation of the number of diet-attributable cancer cases owing to a concentration of increased risk of cancer among certain individuals.

The results of this study are also limited by the measurement methods used for dietary intake and by the methodology of selection and participation of people in the 2006 ENNS. Dietary intake was measured during two time points within a period of 2 weeks, and thus the measurements are susceptible to seasonal $^{(72)}$ and random dietary variations ${ }^{(73)}$. In addition, the ENNS had a response rate of $53.1 \%$ (which is relatively high for a national dietary survey ${ }^{(74)}$ ), and thus the present study's results also may be biased by survey selection and participation biases, which may have led to inaccuracies in the results of the 2006 ENNS regarding the actual dietary intake of French adults ${ }^{(75)}$. Survey respondents in general have been observed to have overall better self-reported health and healthier lifestyle behaviours than non-respondents in population surveys ${ }^{(76,77)}$. Therefore, the dietary intake of respondents to the 2006 ENNS may result in a lower overall cancer risk to these individuals than would the dietary intake of the general population of France.

This study assumed a 10-year average latency period between dietary intake and the diagnosis of cancer. The use of a 10-year latency period was chosen so that the results of the present study would be comparable to results from previous studies in Australia and the $\mathrm{UK}^{(45,46,78)}$. Furthermore, this latency period is in line with the findings of Grundy et al. on the latency period between insufficient fibre intake, red and processed meat consumption and insufficient fruit and vegetable consumption and the development of cancer. Indeed, Grundy et $a l .{ }^{(79)}$ observed that the latency period ranged from 6 to 20 years for the development of cancers related to insufficient fibre intake, from 10 to 14 years for the development of colorectal cancers related to red and processed meat consumption ${ }^{(80)}$ and from 4 to 9 years for the development of cancers related to insufficient fruit and vegetable intakes ${ }^{(81)}$. Furthermore, the risk of cancer is likely owing to long-term dietary intake; however, population-level exposure data, as well as the RR for long-term dietary patterns and the risk of developing cancer, are scarce or unavailable ${ }^{(12)}$.

There are limitations to the RR used. First, as previously mentioned, diet is highly correlated to other risk factors for cancer, such as smoking, obesity, insufficient physical activity and sedentary behaviours ${ }^{(50,51)}$. Even when correcting for these confounders, there is the potential for residual confounding if the risk factors are not measured accurately or in enough detail $^{(82)}$. In addition, the risk of colorectal cancer associated with dairy product intake was reported only for total dairy products $(\mathrm{g} / \mathrm{d})$, milk $(\mathrm{g} / \mathrm{d})$ and cheese $(\mathrm{g} / \mathrm{d})$ intake ${ }^{(83)}$. However, dairy product intake data were only available based on serving size. Therefore, the RR for total dairy product intake was modelled based on the RR for milk intake adjusted to dairy product serving size. Furthermore, the WCRF CUP has assessed that there is only limited suggestive evidence of an association between cheese intake and colorectal cancer risk ${ }^{(20)}$, whereas there is probable evidence of an association between milk intake and colorectal cancer risk ${ }^{(20)}$. Last, in the cases of oral cavity, pharyngeal and laryngeal cancers related to vegetable intake, and of nasopharyngeal and oesophageal cancers related to fruit and vegetable intakes, previous WRCF meta-analyses were out-of-date, and thus RR data were estimated by combining data from large cohort studies ${ }^{(84-86)}$.

The presented analysis also did not incorporate uncertainties into the diet-attributable cancer estimates. This is owing to uncertainties in the cancer data obtained from the FRANCIM, which did not report the uncertainties resulting from the modelling and estimation processes.

\section{Conclusions}

Unfavourable dietary habits led to a substantial number of new cancer cases in France; however, there is a large degree of uncertainty as to how many cancer cases are attributable to these habits. Accordingly, additional research on the causal relationship between the intake of various dietary components and the risk of developing cancer is needed to better describe the burden of new cancer cases owing to diet, as well as to better inform the formation, prioritisation and implementation of national public health guidelines ${ }^{(2,3,9,10)}$.

\section{Acknowledgements}

The authors thank Drs D. Max Parkin, Lesley Rushton and Jürgen Rehm, the Steering Committee of the project 'Définition des priorités pour la prévention du cancer en France métropolitaine: la fraction de cancers attribuables aux modes de vie et aux facteurs environnementaux'.

I. S. has received funds from L'Institut National Du Cancer (grant no. 2015-002) for the project 'Définition des priorités pour la prévention du cancer en France métropolitaine: la fraction de cancers attribuables aux modes de vie et aux facteurs environnementaux'.

F. B. and I. S. conceptualised the study; K. D. S., C. M. M., M. J., H. F., M.-C. B.-R., V. D., P. F., C. H., I. M., M. T., F. B. and I. S. devised the methodology; K. D. S. performed formal analysis; 
K. D. S., C. M. M. and V. D. curated the data; K. D. S., C. M. M., M. J., H. F., M.-C. B.-R., V. D., P. F., C. H., I. M., M. T., F. B. and I. S. contributed to writing the original draft; K. D. S., C. M. M., M. J., H. F., M.-C. B.-R., V. D., P. F., C. H., I. M., M. T., F. B. and I. S. reviewed and edited the manuscript; K. D. S. carried out data visualisation; I. S. supervised the study; K. D. S., C. M. M. and I. S. were involved in project administration.

Ethics approval was not required, as this study involved secondary data analyses only.

The authors declare that there are no conflicts of interest.

\section{Supplementary material}

For supplementary material/s referred to in this article, please visit https://doi.org/10.1017/S0007114518002544

\section{References}

1. Aune D, Giovannucci E, Boffetta P, et al. (2016) Fruit and vegetable intake and the risk of cardiovascular disease, total cancer and all-cause mortality - a systematic review and dose-response meta-analysis of prospective studies. Int J Epidemiol 46, 1029-1056.

2. Institut national de prévention et d'éducation pour la santé (2002) La santé vient en mangeant: le guide alimentaire pour tous (Health Comes with Eating: The Food Guide for All). Paris: Institut national de prévention et d'éducation pour la santé.

3. Ministère du Travail de l'Emploi et de la Santé (2011) Programme national nutrition santé 2011-2015. Paris: Ministère du Travail, de l'Emploi et de la Santé.

4. Forouzanfar MH, Alexander L, Anderson HR, et al. (2015) Global, regional, and national comparative risk assessment of 79 behavioural, environmental and occupational, and metabolic risks or clusters of risks in 188 countries, 1990-2013: a systematic analysis for the Global Burden of Disease Study 2013. Lancet 386, 2287-2323.

5. World Cancer Research Fund and American Institute for Cancer Research (2007) Food, Nutrition, Physical Activity, and the Prevention of Cancer: A Global Perspective. Washington, DC: American Institute for Cancer Research.

6. International Agency for Research on Cancer (2008) IARC Working Group Reports Volume 5: Vitamin D and Cancer. Lyon: International Agency for Research on Cancer.

7. Demeyer D, Mertens B, De Smet S, et al. (2015) Mechanisms linking colorectal cancer to the consumption of (processed) red meat: a review. Crit Rev Food Sci Nutr 56, 2747-2766.

8. Lock K, Pomerleau J, Causer L, et al. (2005) The global burden of disease attributable to low consumption of fruit and vegetables: implications for the global strategy on diet. Bull World Health Organ 83, 100-108.

9. Nishida C, Uauy R, Kumanyika S, et al. (2004) The joint WHO/ FAO expert consultation on diet, nutrition and the prevention of chronic diseases: process, product and policy implications. Public Health Nutr 7, 245-250.

10. World Health Organization (2003) Diet, Nutrition and the Prevention of Chronic Diseases: WHO Technical Report Series 916. Geneva: World Health Organization.

11. Murray CJ \& Lopez AD (1997) Global mortality, disability, and the contribution of risk factors: Global Burden of Disease Study. Lancet 349, 1436-1442.

12. Key TJ, Schatzkin A, Willett WC, et al. (2004) Diet, nutrition and the prevention of cancer. Public Health Nutr 7, 187-200.
13. Doll R \& Peto R (1981) The causes of cancer: quantitative estimates of avoidable risks of cancer in the United States today. J Natl Cancer Inst 66, 1192-1308.

14. Armstrong B \& Doll R (1975) Environmental factors and cancer incidence and mortality in different countries, with special reference to dietary practices. Int J Cancer 15, 617-631.

15. Hedrick VE, Dietrich AM, Estabrooks PA, et al. (2012) Dietary biomarkers: advances, limitations and future directions. Nutr J 11, 109.

16. Levin ML (1953) The occurrence of lung cancer in man. Acta Unio Int Contra Cancrum 9, 531-541.

17. Bouvard V, Loomis D, Guyton KZ, et al. (2015) Carcinogenicity of consumption of red and processed meat. Lancet Oncol 16, 1599-1600.

18. World Cancer Research Fund International, American Institute for Cancer Research (2016) Continuous Update Project Report: Diet, Nutrition, Physical Activity and Oesophageal Cancer. London: World Cancer Research Fund International.

19. World Cancer Research Fund International, American Institute for Cancer Research (2016) Continuous Update Project Report: Food, Nutrition, Physical Activity, and Stomach Cancer. London: World Cancer Research Fund International.

20. World Cancer Research Fund International, American Institute for Cancer Research (2011) Continuous Update Project Report: Food, Nutrition, Physical Activity, and the Prevention of Colorectal Cancer. London: World Cancer Research Fund International.

21. World Cancer Research Fund International, American Institute for Cancer Research (2015) Continuous Update Project Report: Food, Nutrition, Physical Activity, and the Prevention of Liver Cancer. London: World Cancer Research Fund International.

22. World Cancer Research Fund International, American Institute for Cancer Research (2015) Continuous Update Project Report: Diet, Nutrition, Physical Activity and Gallbladder Cancer. London: World Cancer Research Fund International.

23. World Cancer Research Fund International, American Institute for Cancer Research (2012) Continuous Update Project Report: Food, Nutrition, Physical Activity, and the Prevention of Pancreatic Cancer. London: World Cancer Research Fund International.

24. World Cancer Research Fund International, American Institute for Cancer Research (2011) Continuous Update Project Report: Food, Nutrition, Physical Activity, and the Prevention of Breast Cancer. London: World Cancer Research Fund International.

25. World Cancer Research Fund International, American Institute for Cancer Research (2013) Continuous Update Project Report: Diet, Nutrition, Physical Activity and the Prevention of Endometrial Cancer. London: World Cancer Research Fund International.

26. World Cancer Research Fund International, American Institute for Cancer Research (2014) Continuous Update Project Report: Food, Nutrition, Physical Activity, and the Prevention of Ovarian Cancer 2014. London: World Cancer Research Fund International.

27. World Cancer Research Fund International, American Institute for Cancer Research (2014) Continuous Update Project Report: Food, Nutrition, Physical Activity, and Prostate Cancer. London: World Cancer Research Fund International.

28. World Cancer Research Fund International, American Institute for Cancer Research (2015) Continuous Update Project Report: Diet, Nutrition, Physical Activity and Kidney Cancer. London: World Cancer Research Fund International.

29. World Cancer Research Fund International, American Institute for Cancer Research (2015) Continuous Update Project Report: Diet, Nutrition, Physical Activity and Bladder Cancer. London: World Cancer Research Fund International. 
30. Institut National Du Cancer (2015) Nutrition et prévention primaire des cancers: actualisation des données synthèse (Nutrition and Primary Prevention of Cancer: Update of Summary Data). Boulogne-Billancourt: Institut National du Cancer.

31. Unité de surveillance et d'épidémiologie nutritionnelle (2007) Étude nationale nutrition santé: situation nutritionnelle en France en 2006 selon les indicateurs d'objectif et les repères du Programme national nutrition santé (PNNS) (National Nutrition and Health Study: Nutritional Situation in France in 2006 According to the Target Indicators and the Benchmarks of the National Health and Nutrition Program (PNNS)). Paris: Institut de veille sanitaire, Université de Paris.

32. Dubuisson C, Lioret S, Touvier M, et al. (2010) Trends in food and nutritional intakes of French adults from 1999 to 2007: results from the INCA surveys. Br J Nutr 103, 1035-1048.

33. Le Moullec N, Deheeger M, Preziosi P, et al. (1996) Validation du manuel-photos utilisé pour l'enquête alimentaire de l'étude SU.VI.MAX (Validation of photographic document used to estimate the amounts of foods eaten by subjects in the SU.VI. MAX study). Cahe Nutr Diet 31, 158-164.

34. Hercberg S, Arnault N \& Astorg P (2005) Tables de composition des aliments SU.VI.MAX (Food Composition Tables: SU. VI.MAX Study). Paris: Anthropos Economica.

35. Black AE (2000) Critical evaluation of energy intake using the Goldberg cut-off for energy intake: basal metabolic rate. A practical guide to its calculation, use and limitations. Int J Obes 24, 1119-1130.

36. World Cancer Research Fund International (2017) Our cancer prevention recommendations: plant foods. http://www.web citation.org/6pCMU6siU (accessed March 2017).

37. World Cancer Research Fund International (2017) Our cancer prevention recommendations: animal foods. http://www. webcitation.org/6pCMLmdTN (accessed March 2017).

38. World Cancer Research Fund International (2017) Our cancer prevention recommendations: preservation, processing, preparation. http://www.webcitation.org/6pCM7Vs76 (accessed March 2017).

39. Parkin D (2011) 5. Cancers attributable to dietary factors in the UK in 2010: I. Low consumption of fruit and vegetables. Br J Cancer 105, S24-S26.

40. Haut Conseil de la santé publique (2017) Révision des repères alimentaires pour les adultes du futur programme national nutrition santé 2017-2021 (Review of Food Benchmarks for Adults in the Future National Nutrition and Health Program 2017-2021). Paris: Haut Conseil de la santé publique.

41. Shield KD, Parkin DM, Whiteman DC, et al. (2016) Population attributable and preventable fractions: cancer risk factor surveillance, and cancer policy projection. Curr Epidemiol Rep $\mathbf{3}$ 201-211.

42. Santé Pays de la Loire (2015) Le réseau FRANCIM: Les registres des cancers en France (The FRANCIM Network: Cancer Registries in France). Nantes: Santé Pays de la Loire.

43. Institut national de la statistique et des études économiques (2015) Statistical Operation: Population Estimates. Paris: Institut national de la statistique et des études économiques.

44. Parkin DM (2011) 1. The fraction of cancer attributable to lifestyle and environmental factors in the UK in 2010. Br J Cancer 105, Suppl. 2, S2-S5.

45. Nagle CM, Wilson LF, Hughes MCB, et al. (2015) Cancers in Australia in 2010 attributable to inadequate consumption of fruit, non-starchy vegetables and dietary fibre. Aust $N \mathrm{ZJ}$ Public Health 39, 422-428.

46. Nagle CM, Wilson LF, Hughes MCB, et al. (2015) Cancers in Australia in 2010 attributable to the consumption of red and processed meat. Aust N Z J Public Health 39, 429-433.
47. Abnet CC (2007) Carcinogenic food contaminants. Cancer Invest 25, 189-196.

48. Loomis D, Guyton KZ, Grosse Y, et al. (2016) Carcinogenicity of drinking coffee, mate, and very hot beverages. Lancet Oncol 17, 877-878

49. Temple NJ \& Gladwin KK (2003) Fruit, vegetables, and the prevention of cancer: research challenges. Nutrition 19 , 467-470.

50. Key TJ, Allen NE, Spencer EA, et al. (2002) The effect of diet on risk of cancer. Lancet $\mathbf{3 6 0}, 861-868$.

51. Ma Y, Bertone ER, Stanek EJ, et al. (2003) Association between eating patterns and obesity in a free-living US adult population. Am J Epidemiol 158, 85-92.

52. French Agency for Food, Environmental and Occupational Health and Safety (2015) Opinion of the French Agency for Food, Environmental and Occupational Health and Safety on the Updating of the PNNS Guidelines: Revision of the Guidelines Relating to Physical Activity and Sedentarity. Maisons-Alfort: French Agency for Food, Environmental and Occupational Health and Safety.

53. World Health Organization (2006) Global Strategy on Diet, Physical Activity and Health: A Framework to Monitor and Evaluate Implementation. Geneva: World Health Organizaiton.

54. Popkin BM \& Gordon-Larsen P (2004) The nutrition transition: worldwide obesity dynamics and their determinants. Int J Obes 28, S2-S9.

55. Institute of Medicine (US) Subcommittee on Interpretation and Uses of Dietary Reference Intakes, Institute of Medicine (US) Standing Committee on the Scientific Evaluation of Dietary Reference Intakes (2000) DRI Dietary Reference Intakes: Applications in Dietary Assessment. Washington, DC: National Academies Press.

56. World Health Organization (2017) 5. Population Nutrient Intake Goals for Preventing Diet-related Chronic Diseases. Geneva: World Health Organization.

57. World Health Organization (2012) Guideline: Sodium Intake for Adults and Children. Geneva: World Health Organization.

58. Scientific Advisory Committee on Nutrition (2015) Carbohydrates and Health. Norwich: The Stationery Office.

59. Food Standards Agency (2007) FSA Nutrient and Food Based Guidelines for UK Institutions. London: Food Standards Agency.

60. National Health and Medical Research Council (2013) Australian Dietary Guidelines. Canberra: Commonwealth of Australia.

61. US Department of Agriculture, US Department of Health and Human Services (2010) Dietary Guidelines for Americans, 2010, 7th ed. Washington, DC: US Government Printing Office.

62. US Department of Agriculture, US Department of Health and Human Services (2016) Dietary Guidelines for Americans, 2015-2020, 8th ed. Washington, DC: US Government Printing Office.

63. Jacques PF \& Tucker KL (2001) Are dietary patterns useful for understanding the role of diet in chronic disease? Am J Clin Nutr 73, 1-2.

64. Kant AK (2004) Dietary patterns and health outcomes. J Am Dent Assoc 104, 615-635.

65. Kesse E, Clavel-Chapelon F \& Boutron-Ruault M-C (2006) Dietary patterns and risk of colorectal tumors: a cohort of French women of the National Education System (E3N). Am J Epidemiol 164, 1085-1093.

66. Hu FB (2002) Dietary pattern analysis: a new direction in nutritional epidemiology. Curr Opin Lipidol 13, 3-9.

67. Bertin M, Touvier M, Dubuisson C, et al. (2016) Dietary patterns of French adults: associations with demographic, 
socio-economic and behavioural factors. J Hum Nutr Diet 29 , 241-254.

68. Miller AB \& Linseisen J (2010) Achievements and future of nutritional cancer epidemiology. Int J Cancer 126, 1531-1537.

69. Ruiz RB \& Hernández PS (2014) Diet and cancer: risk factors and epidemiological evidence. Maturitas 77, 202-208.

70. Englyst H, Bingham S, Runswick S, et al. (1988) Dietary fibre (non-starch polysaccharides) in fruit, vegetables and nuts. J Hum Nutr Diet 1, 247-286.

71. Fiolet T, Srour B, Sellem L, et al. (2018) Consumption of ultraprocessed foods and cancer risk: results from NutriNet-Santé prospective cohort. BMJ 360, k322.

72. Bonifacj C, Gerber M, Scali J, et al. (1997) Comparison of dietary assessment methods in a southern French population: use of weighed records, estimated-diet records and a food-frequency questionnaire. Eur J Clin Nutr 51, 217-231.

73. Schatzkin A, Kipnis V, Carroll RJ, et al. (2003) A comparison of a food frequency questionnaire with a 24-hour recall for use in an epidemiological cohort study: results from the biomarkerbased Observing Protein and Energy Nutrition (OPEN) study. Int J Epidemiol 32, 1054-1062.

74. Guo Y, Kopec JA, Cibere J, et al. (2016) Population survey features and response rates: a randomized experiment. Am J Public Health 106, 1422-1426.

75. Groves RM (2004) Survey Errors and Survey Costs. Hoboken, NJ: John Wiley \& Sons.

76. Korkeila K, Suominen S, Ahvenainen J, et al. (2001) Nonresponse and related factors in a nation-wide health survey. Eur J Epidemiol 17, 991-999.

77. Van Loon AJM, Tijhuis M, Picavet HSJ, et al. (2003) Survey nonresponse in the Netherlands: effects on prevalence estimates and associations. Ann Epidemiol 13, 105-110.

78. Parkin D, Boyd L \& Walker L (2011) 16. The fraction of cancer attributable to lifestyle and environmental factors in the UK in 2010: summary and conclusions. $\mathrm{Br} J$ Cancer 105, S77-S81.

79. Grundy A, Poirier AE, Khandwala F, et al. (2017) Cancer incidence attributable to insufficient fibre consumption in Alberta in 2012. CMAJ Open 5, E7-E13.
80. Grundy A, Poirier AE, Khandwala F, et al. (2016) Cancer incidence attributable to red and processed meat consumption in Alberta in 2012. CMAJ Open 4, E768-E775.

81. Grundy A, Poirier AE, Khandwala F, et al. (2016) Cancer incidence attributable to insufficient fruit and vegetable consumption in Alberta in 2012. CMAJ Open 4, E760-E767.

82. Rothman KJ, Greenland S \& Lash TL (2008) Modern Epidemiology. Philadelphia, PA: Lippincott Williams \& Wilkins.

83. Aune D, Lau R, Chan D, et al. (2012) Dairy products and colorectal cancer risk: a systematic review and meta-analysis of cohort studies. Ann Oncol 23, 37-45.

84. Freedman ND, Park Y, Subar AF, et al. (2008) Fruit and vegetable intake and head and neck cancer risk in a large United States prospective cohort study. Int J Cancer 122, 2330-2336.

85. Bradbury KE, Appleby PN \& Key TJ (2014) Fruit, vegetable, and fiber intake in relation to cancer risk: findings from the European Prospective Investigation into Cancer and Nutrition (EPIC). Am J Clin Nutr 100, 394S-398S.

86. Freedman ND, Park Y, Subar AF, et al. (2007) Fruit and vegetable intake and esophageal cancer in a large prospective cohort study. Int J Cancer 121, 2753-2760.

87. Vieira AR, Abar L, Vingeliene S, et al. (2016) Fruits, vegetables and lung cancer risk: a systematic review and meta-analysis. Ann Oncol 27, 81-96.

88. Aune D, Chan DS, Lau R, et al. (2011) Dietary fibre, whole grains, and risk of colorectal cancer: systematic review and dose-response meta-analysis of prospective studies. Br Med J 343, d6617.

89. Aune D, Chan D, Greenwood D, et al. (2012) Dietary fiber and breast cancer risk: a systematic review and meta-analysis of prospective studies. Ann Oncol 23, 1394-1402.

90. Chan DS, Lau R, Aune D, et al. (2011) Red and processed meat and colorectal cancer incidence: meta-analysis of prospective studies. PLOS ONE 6, e20456.

91. Larsson S \& Wolk A (2012) Red and processed meat consumption and risk of pancreatic cancer: meta-analysis of prospective studies. Br J Cancer 106, 603-607.

92. Alexander DD, Mink PJ, Cushing CA, et al. (2010) A review and meta-analysis of prospective studies of red and processed meat intake and prostate cancer. Nutr J 9, 50. 